\title{
Experimental Study on Tribological Properties of Laser Textured 45 Steel
}

\section{Surface}

\author{
Zhi Peng $\mathrm{LI}^{1, \mathrm{a}}$, Jin $\mathrm{He} \mathrm{WU}^{1}, \mathrm{Na} \mathrm{WU}^{2}$ and Dong Xu LI ${ }^{1}$ \\ ${ }^{1}$ school of mechanical and electrical engineering, Jiangsu Normal University, 221116 Xuzhou, China \\ ${ }^{2}$ school of mechanical and electrical engineering, China University of Mining and Technology, 221116 Xuzhou, China
}

\begin{abstract}
In order to study the influence of pits' size parameters on the tribological properties of textured friction pairs, using the Nd:YAG laser micro machining system and the "single pulse at the same point, interval more times" processing technics to process the pits on the surface of 45 steel. The dimension parameters of pits texture were obtained by orthogonal experimental design. The tribological experiment of GCr15 pin /45 steel disc was carried out by UMT-2 test machine. The surface morphology of the specimens was analyzed by using scanning electron microscopy. The experimental results show that the pits texture on the surface of 45 steel can effectively reduce the friction coefficient and the wear on the condition of oil-rich lubrication. The textured specimen with diameter $60 \mu \mathrm{m}$, depth $6 \mu \mathrm{m}$ and surface density $10 \%$ has the lowest friction coefficient, and the friction coefficient is reduced by $21 \%$ compared with the smooth specimen. By analyzing the wear morphology on the surface of 45 steel, it is found that the surface of pits texture can obviously reduce the wear.
\end{abstract}

Keywords: Surface micro-texture; Orthogonal experimental design; Lubrication; Tribological properties

\section{Introduction}

The friction and lubrication performance have an important influence on the operation efficiency and service life of the mechanical system. These years, based on some research results, the surface with a certain texture and morphology has better wear resistance ${ }^{[1-5]}$. The texture with different sizes and shapes can be processed on the samples surface by using laser micro machining system. The processed textured samples were studied by friction and wear test, which show good effect of anti-friction and promote the lubrication. At the same time, it has been applied to the cylinder liner-piston ring friction pair of internal combustion engine ${ }^{[6-7]}$. Fu et al. ${ }^{[8]}$ reported an experimental study on the tribological

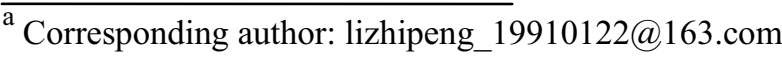

properties of the textured surfaces, they put forward that the pits texture have good lubrication performance. Meanwhile, when the pit surface density is $15 \%$ and the depth is $5 \mu \mathrm{m}$, the friction coefficient of the texture sample is the lowest. Wan et al. ${ }^{[9]}$ processed on the surface of GCr15 steel plate, and studied the effect of sliding speed on the lubrication state of textured surface, they put forward the lubrication state of surface texture changes from the mixed lubrication to the fluid lubrication at a lower speed. Moreover, the existence of micro porous texture can improve the bearing capacity of oil film and reduce the width of wear scar. Under the different surface densities, the effects of surface texture on the dry friction and wear properties were studied by using the ring-block line contact friction and wear test. The hardness increases 
and the wear rate decreases in the textured region. In a certain range, the wear rate decreases with the increase of the density of the textured surface ${ }^{[10]}$. At present, most of the research on the surface texture are the contrast experiments, which have not concluded the optimal surface texture profile and parameters. Therefore, the further research on tribology experiment are also needed.

In this paper, we used $\mathrm{Nd}$ :YAG laser micro machining system to process the pits on the surface of 45 steel, the dimension parameters of pits texture were obtained by orthogonal experimental design, and then carried out experiments on the UMT-2 test machine. The fundamental aim of this work is to investigate the effects of friction coefficient and wear morphology on the surface of 45 steel under different dimension parameters.

\section{Experimental part}

\subsection{Laboratory equipment and materials}

In this experiment, we used a $\mathrm{Q}$ switched diode-pumped $\mathrm{Nd}$ :YAG laser to process the pits on the surface of 45 steel. The material of the upper test piece is $\mathrm{GCr} 15$, the diameter is $6 \mathrm{~mm}$, the length is $20 \mathrm{~mm}$, and the hardness is HRC65. The material of the lower test piece is 45 steel, the diameter is $30 \mathrm{~mm}$, the thickness is $8 \mathrm{~mm}$, and the hardness is HRC50.

\subsection{Orthogonal experimental design and the processing of pit textures}

(1) Determine the experimental factors and levels: choose pit diameter, pit depth and pit surface density as the three factors of the experiment. The different values taken by each factor are the level of this factor, the factors and levels of the experiment are shown in Table 1.

Table 1. The graph of factors and levels.

\begin{tabular}{|c|c|c|c|}
\hline Levels & $\begin{array}{c}A \\
\text { Pit diameter } \\
(\mu \mathrm{m})\end{array}$ & $\begin{array}{c}B \\
\text { Pit depth } \\
(\mu \mathrm{m})\end{array}$ & $\begin{array}{c}C \\
\text { Pit surface density } \\
(\%)\end{array}$ \\
\hline 1 & 40 & 4 & 5 \\
\hline 2 & 60 & 6 & 15 \\
\hline 3 & 90 & 8 & 10 \\
\hline
\end{tabular}

(2) Choose the orthogonal table to design experimental plan: according to the factors and levels of the experiment, choose $L_{9}\left(3^{4}\right)$ orthogonal experiment table. In Table 2, the $A, B, C$ and $D$ respectively represent the pit diameter, the pit depth, the pit surface density and the empty column. Orthogonal experimental scheme is shown in Table 2.

Table 2. The orthogonal experimental form.

\begin{tabular}{|c|c|c|c|c|c|}
\hline Experiment serial number & $\begin{array}{c}A \\
\text { Pit diameter }(\mu \mathrm{m})\end{array}$ & $\begin{array}{c}B \\
\text { Pit depth }(\mu \mathrm{m})\end{array}$ & $\begin{array}{c}C \\
\text { Pit surface density }(\%)\end{array}$ & $\begin{array}{c}D \\
\text { Empty column }\end{array}$ & Experimental program \\
\hline Untextured surface & 0 & 0 & 0 & & \\
\hline Sample 1 & $1(40)$ & $1(4)$ & $1(5)$ & 1 & $A_{1} B_{1} C_{1}$ \\
\hline Sample 2 & $1(40)$ & $2(6)$ & $2(15)$ & 2 & $A_{1} B_{2} C_{2}$ \\
\hline Sample 3 & $1(40)$ & $3(8)$ & $3(10)$ & 3 & $A_{1} B_{3} C_{3}$ \\
\hline Sample 4 & $2(60)$ & $1(4)$ & $2(15)$ & 3 & $A_{2} B_{1} C_{2}$ \\
\hline Sample 5 & $2(60)$ & $2(6)$ & $3(10)$ & 1 & $A_{2} B_{2} C_{3}$ \\
\hline Sample 6 & $2(60)$ & $3(8)$ & $1(5)$ & 2 & $A_{2} B_{3} C_{1}$ \\
\hline Sample 7 & $3(90)$ & $1(4)$ & $3(10)$ & 2 & $A_{3} B_{1} C_{3}$ \\
\hline Sample 8 & $3(90)$ & $2(6)$ & $1(5)$ & 3 & $A_{3} B_{2} C_{1}$ \\
\hline Sample 9 & $3(90)$ & $3(8)$ & $2(15)$ & 1 & $A_{3} B_{3} C_{2}$ \\
\hline
\end{tabular}

(3) Texture processing procedure: Firstly, the surface of 45 steel was grinded by using 160, 320, 500, 800, 1000, 1200 sandpapers, then the sample surface was polished by diamond polishing liquid with the diameter is $0.1 \mu \mathrm{m}$, and the surface roughness of the sample is about $0.1 \mu \mathrm{m}$ after polishing. Secondly, use the "single pulse at the same point, interval more times" processing technics to process the pits on the surface of 45 steel. Figure 1 is the morphology of pit processed by laser. By using Keyence's high speed digital micro system can measure the diameter 
of the pit is about $60 \mu \mathrm{m}$, and the depth is about $4 \mu \mathrm{m}$. As shown in Figure 1, the residue appeared around the texture is formed by the molten metal splashing and curdling in the process of machining. The adhesion between the specimen and the residue is small, it is easy to use sandpaper to wipe the residue. Thirdly, the 45 steel surface was lightly polished to remove some solid residues from the edge of the pits after the samples were processed, then use the ultrasonic cleaner to clean the surface of 45 steel. Finally, dry the 45 steel, and put it in the dry plastic box.

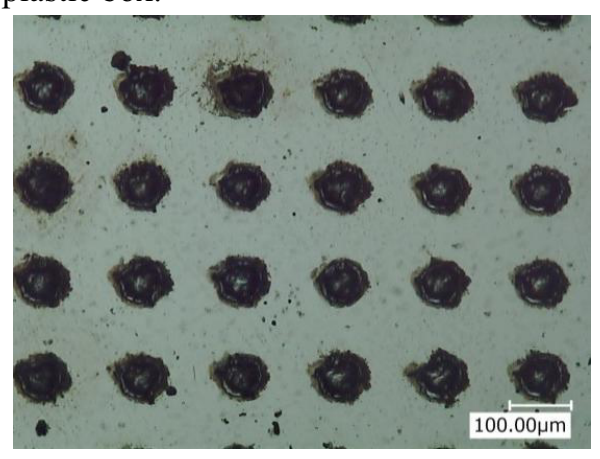

Figure 1. The surface texture were processed by laser with diameter $60 \mu \mathrm{m}$ and depth $4 \mu \mathrm{m}$.

\subsection{Tribology experiment}

The UMT-2 testing machine is employed to conduct the tribological experiments, adopt the friction pair of $\mathrm{GCr} 15$ pin/45 steel disc. The upper test piece is still, the lower test piece is in a reciprocating motion and reciprocating stroke is $15 \mathrm{~mm}$. In the experiment, dripping about $0.2 \mathrm{ml}$ lubricating oil into the friction contact zone of pin and disc every $2 \mathrm{~min}$, the oil number is $5 \mathrm{~W}-30$. The experiment was carried out at $20^{\circ} \mathrm{C}$ for $15 \mathrm{~min}$. After the end of the experiment, use the ultrasonic cleaner to clean the surface of 45 steel, then dry the 45 steel. The wear scar and surface morphology of the specimens were observed and analyzed by using scanning electron microscopy.

\section{Results and discussion}

The measured values of the average friction coefficient of the smooth surface and the nine groups of pits surface were obtained by the UMT-2 test machine. The measured values of the friction coefficient of orthogonal experiment are shown in Table 3.

\subsection{Range analysis of specimens with different pit sizes}

The range analysis method is used to deal with the results of orthogonal experiment, it can also determine the primary and secondary subsequence of influencing factors of pit diameter, pit depth and pit surface density. Table 4 is the range analysis of the experimental results of different pit diameters, different pit depths and different pit surface densities.

Table 3. The measured values of the friction coefficient of orthogonal experiment.

\begin{tabular}{|c|c|c|c|c|}
\hline $\begin{array}{c}\text { Experiment serial } \\
\text { number }\end{array}$ & $\begin{array}{c}A \\
\text { Pit diameter }(\mu \mathrm{m})\end{array}$ & $\begin{array}{c}B \\
\text { Pit depth }(\mu \mathrm{m})\end{array}$ & $\begin{array}{c}C \\
\text { Pit surface density }(\%)\end{array}$ & $\begin{array}{c}\text { Friction } \\
\text { coefficient }\end{array}$ \\
\hline Untextured surface & 0 & 0 & 0 & 0.143 \\
\hline Sample 1 & 40 & 4 & 5 & 0.142 \\
\hline Sample 2 & 40 & 6 & 15 & 0.134 \\
\hline Sample 3 & 40 & 8 & 10 & 0.194 \\
\hline Sample 4 & 60 & 4 & 10 & 0.143 \\
\hline Sample 5 & 60 & 6 & 5 & 0.113 \\
\hline Sample 6 & 60 & 8 & 10 & 0.148 \\
\hline Sample 7 & 90 & 4 & 5 & 0.126 \\
\hline Sample 8 & 90 & 6 & 15 & 0.140 \\
\hline Sample 9 & 90 & 8 & & 0.119 \\
\hline
\end{tabular}

Table 4. The range analysis of experimental results.

\begin{tabular}{|c|c|c|c|c|c|}
\hline \multirow{2}{*}{ Experiment serial number } & $A$ & $B$ & $C$ & $D$ & Friction \\
& Pit diameter $(\mu \mathrm{m})$ & Pit depth $(\mu \mathrm{m})$ & $\begin{array}{c}\text { Pit surface density } \\
(\%)\end{array}$ & $\begin{array}{c}\text { Empty column } \\
\text { coefficient }\end{array}$ \\
\hline
\end{tabular}




\begin{tabular}{|c|c|c|c|c|c|}
\hline Sample 1 & $1(40)$ & $1(4)$ & $1(5)$ & 1 & 0.142 \\
\hline Sample 2 & $1(40)$ & $2(6)$ & $2(15)$ & 2 & 0.134 \\
\hline Sample 3 & $1(40)$ & $3(8)$ & $3(10)$ & 3 & 0.194 \\
\hline Sample 4 & $2(60)$ & $1(4)$ & $2(15)$ & 3 & 0.143 \\
\hline Sample 5 & $2(60)$ & $2(6)$ & $3(10)$ & 1 & 0.113 \\
\hline Sample 6 & $2(60)$ & $3(8)$ & $1(5)$ & 2 & 0.148 \\
\hline Sample 7 & $3(90)$ & $1(4)$ & $3(10)$ & 2 & 0.126 \\
\hline Sample 8 & $3(90)$ & $2(6)$ & $1(5)$ & 3 & 0.140 \\
\hline Sample 9 & $3(90)$ & $3(8)$ & $2(15)$ & 1 & 0.119 \\
\hline$K_{1}$ & 0.470 & 0.411 & 0.430 & & \\
\hline$K_{2}$ & 0.404 & 0.387 & 0.396 & & \\
\hline$K_{3}$ & 0.385 & 0.461 & 0.433 & & \\
\hline$k_{1}=K_{1} / 3$ & 0.157 & 0.137 & 0.143 & & \\
\hline$k_{2}=K_{2} / 3$ & 0.135 & 0.129 & 0.132 & & \\
\hline$k_{3}=K_{3} / 3$ & 0.128 & 0.154 & 0.144 & & \\
\hline Range $R$ & 0.029 & 0.025 & 0.012 & & \\
\hline $\begin{array}{c}\text { Primary and secondary } \\
\text { sequence }\end{array}$ & & & $A \quad B \quad C$ & & \\
\hline Optimal scheme & & & $A_{3} B_{2} C_{2}$ & & \\
\hline
\end{tabular}

In Table 4, according to these three factors of the diameter, the depth and the density of the pits surface, the degree of the effect on friction coefficient should be: $A$ (pit diameter $)>B$ (pit depth) $>C$ (pit surface density). The best solution should be $A_{3} B_{2} C_{2}$, namely the pits texture sample with the diameter is $90 \mu \mathrm{m}$, the depth is $6 \mu \mathrm{m}$ and the surface density is $15 \%$. The best experimental program hasn't been done, it can be found from the advantage of orthogonal table.

\subsection{Tribological properties of specimens with different pit sizes}

Friction coefficient is an important parameter to evaluate the friction characteristics of friction pairs. Through the experiment of pits samples with different size parameters, the friction coefficient of the pit diameter is $60 \mu \mathrm{m}$ and the smooth sample is shown in Figure 2. The friction coefficient of the pit depth is $6 \mu \mathrm{m}$ and the smooth sample is shown in Figure 3.

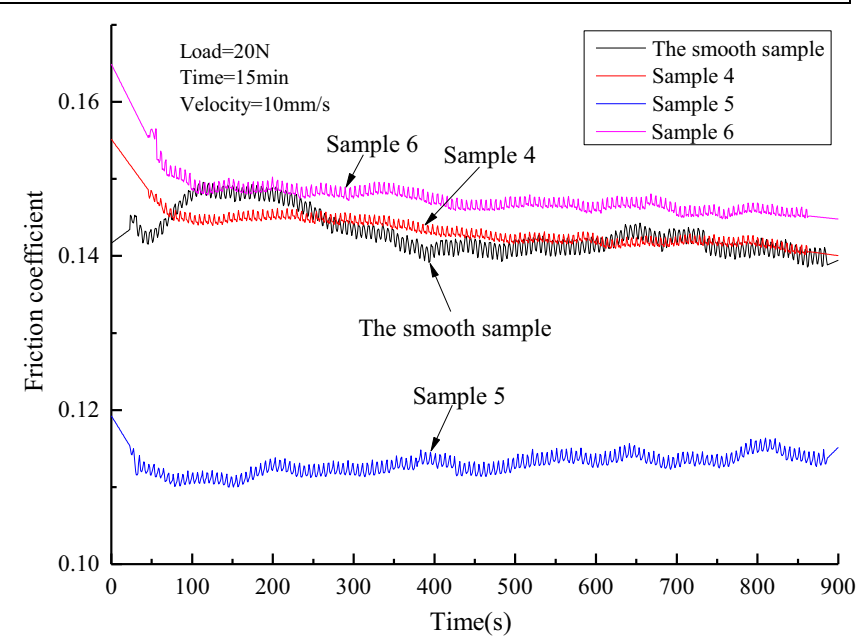

Figure 2. The friction coefficient of the pit diameter is $60 \mu \mathrm{m}$ and the smooth sample. 


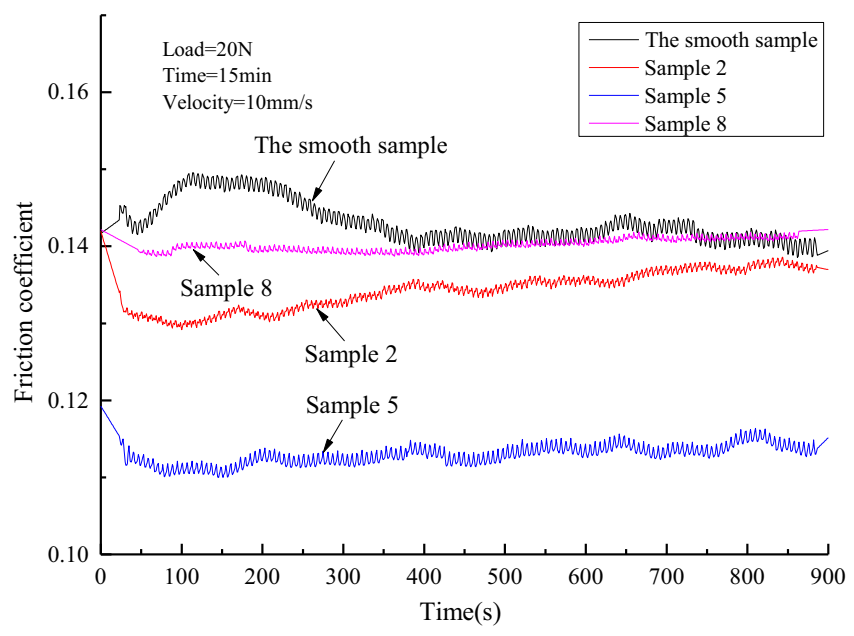

Figure 3. The friction coefficient of the pit depth is $6 \mu \mathrm{m}$ and the smooth sample.

From the Table 3, Figure 2 and Figure 3, we can find that the friction coefficient of sample 1, 2, 5, 7, 8 and 9 is lower than the smooth sample. The results show that the pits textured surface has the effect of reducing friction. However, the friction coefficient of sample 3 and sample 6 are higher than the smooth sample. This is because the diameter of sample 3 is small and the depth of sample 6 is deep, so that the film thickness becomes thin and the lubrication state of the friction pairs changes from fluid lubrication to boundary lubrication. The sample 5 with the diameter is $60 \mu \mathrm{m}$, the depth is $6 \mu \mathrm{m}$ and the surface density is $10 \%$ has the lowest friction coefficient. It shows that the texture parameter of sample 5 is beneficial to increase the thickness of the oil film of the friction pair, it can also be better to store the wear debris and reduce the friction between the friction pairs.

\subsection{Comparison of wear morphologies of specimens with different pit sizes}

Figure 4(a) are the wear scars of smooth surface, which were observed by using scanning electron microscopy. Figure 4 (b) $\sim(f)$ are part of the wear scars between pits of different samples.

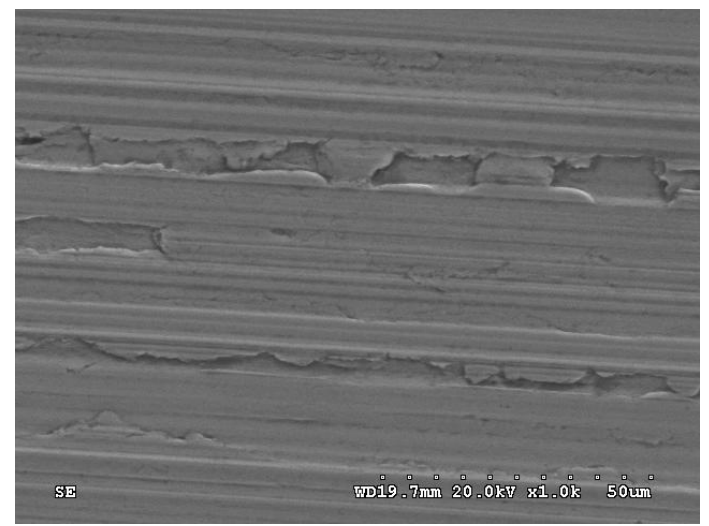

(a) the wear scars of smooth sample

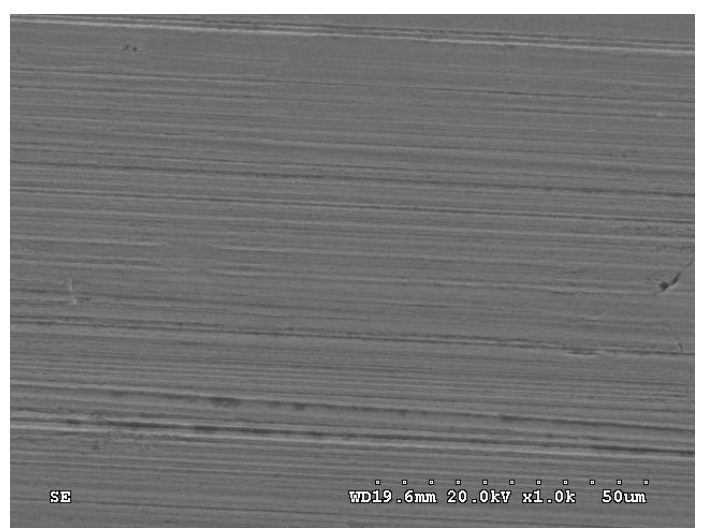

(b) the wear scars of sample 1

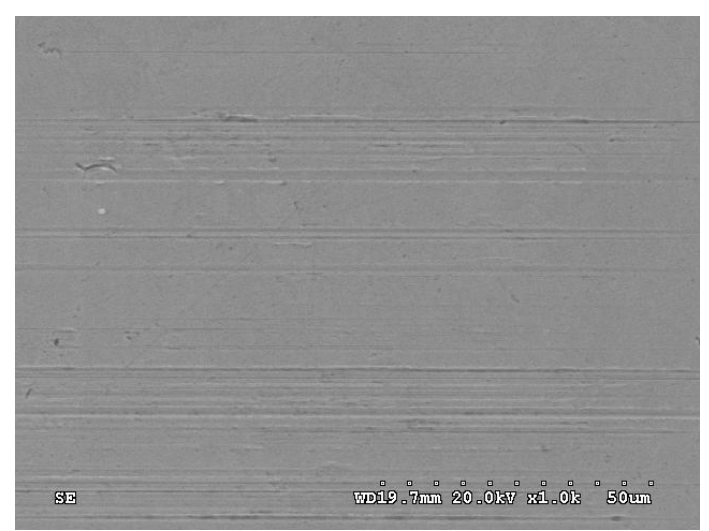

(c) the wear scars of sample 5

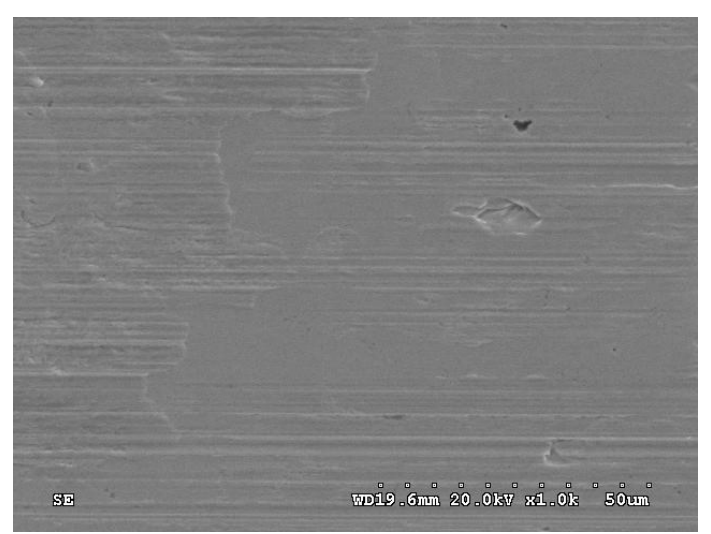

(d) the wear scars of sample 6 


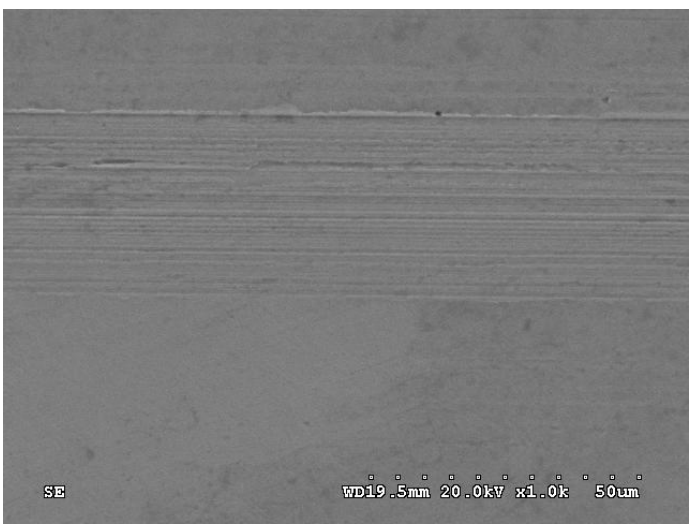

(e) the wear scars of sample 7

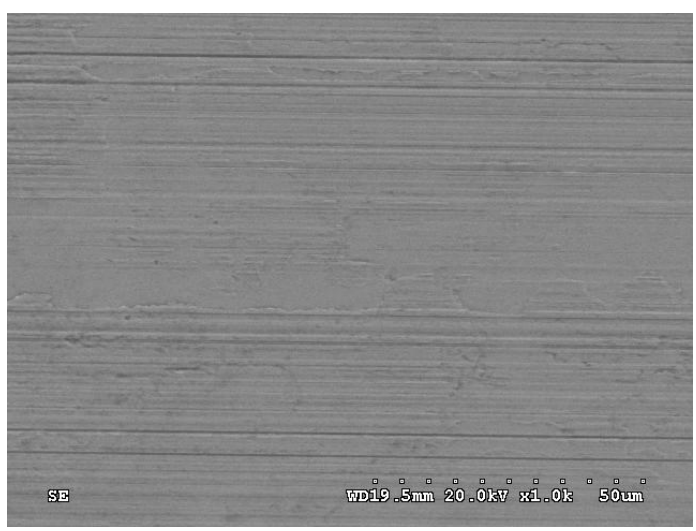

(f) the wear scars of sample 8

Figure 4. Microscopic photographs of the wear scars between pits of different samples.

It can be seen from Figure 4(a), the surface morphology of the smooth sample is relatively rough after wear, surface grinding marks are significant, surface scratches are more serious, the surface appears the obvious furrows, and because of fatigue and adhesive wear, the greater spalling were occurred locally. However, in Figure 4, among the micro images of the wear scars of sample 1, 5, 6, 7 and 8, it can be seen that the wear scars of the pits texture are relatively light compared with smooth sample. This shows that the pits texture can improve the wear resistance of the samples surface, which indicate the superiority of the textured surface. And in the samples of these textured surfaces, their wear traces are a little different. In Figure 4(c), the wear traces of the sample 5 are relatively small, it shows that the surface texture with this size can improve the lubrication on the surface of the friction pair.

\section{Conclusion}

By using the "single pulse at the same point, interval more times" processing technics to process the pits on the surface of 45 steel, and then the tribological experiment of GCr15 pin/45 steel disc was carried out by UMT-2 test machine. The following conclusions can be drawn:

(1) The pit texture can effectively reduce the friction coefficient of the contact surface. When the pit texture sample meets the conditions including that the diameter is $60 \mu \mathrm{m}$, the depth is $6 \mu \mathrm{m}$ and surface density is $10 \%$, the friction coefficient of friction pair is the lowest, and the biggest decline was $21 \%$ compared with the smooth sample.

(2) The surface scratches of the smooth sample are more serious than others, and the greater spalling were occurred locally because of fatigue and adhesive wear. The analysis of the wear morphology on the surface of 45 steel shows that the wear scars of the pits texture are relatively light compared with smooth sample. The surface with pits texture has a significant effect on wear resistance.

\section{References}

1. B. Bhushan, S.R. Ge, Introduction to tribology (China Machine Press, Bei Jing, 2007)

2. C.B. Ma, H. Zhu, J.Q. Li, J. China U. Min. Techno. 39, 244 (2010)

3. Y.K. Zhou, H. Zhu, W. Tang, W.Q. Zhang, Lubrication Eng. 37, 45 (2012)

4. J.H. Ji, Y.H. Fu, X.J. Hua, H. Fu, Z.Y. Kang, China Surface Eng. 27, 107 (2014)

5. J. Gandra, H. Krohn, R.M. Miranda, P.Vilaca, L. Quintino, J.F. dos Santos, J. Mater. Processing Techno. 214, 1062 (2014)

6. B.F. Yin, Z.T. Lu, S.J. Liu, Y.H. Fu, Y. Wang, J. Mech. Eng. 48, 91 (2012)

7. B.F. Yin, Y.Q. Qian, Z.T. Lu, B.W. Wang, S. Sun, J. Xi'an Jiaotong Univ. 48, 74 (2014)

8. Y.H. Fu, B.H. Tang, J.H. Ji, H.W. Zhang, X.J. Hua, Lubrication Eng. 38, 19 (2013)

9. Y. Wan, J.L. Li, D.S. Xiong, J. Cent. South Univ. (Sci. Techno.) 46, 4442 (2015)

10. B. Wang, Q.Y. Chang, Y. Qi, Lubrication Eng. 38, 11 (2013) 